\title{
Electric Field Distribution around Contaminating Wire Particles Inside Gas Insulated Bus Duct
}

\author{
Mousa A. Abd-Allah ${ }^{1}$, Sayed A. Ward ${ }^{2}$, and Amr A. Youssef ${ }^{3}$ \\ Electrical Engineering Department, Faculty of Engineering at Shoubra, \\ Benha University, Cairo, Egypt \\ eng_power_amr2011@yahoo.com
}

\begin{abstract}
The presence of metallic contaminating particles lowered the dielectric strength of the gas sharply. The determination of the insulation breakdown inside gas insulated bus duct requires the knowledge of the field distribution inside it. Finite Element Method (FEM) has been used throughout this work, for its favorable accuracy, to calculate the electric field distribution inside the bus duct. In this paper, the electrostatic modeling of gas insulated bus duct (GIBD) with particle contamination is studied. The effect of particle length, hemi-spherical radius and ratio $(\mathrm{L} / \mathrm{r})$ on the electric field values is presented. The effect of the dielectric coating of the inner surface of enclosure, is presented and discussed. Multi-contaminating fixed particles are considered in this work and the electric field distribution in this case is presented. The effect of particle length and radius of middle fixed particle of multi contaminating particles on the electric field values are also studied. Electric field distribution around disc-spacer with and without an earthed particle contamination is presented and discussed. Finally, the effect of distance between particle and spacer on the electric field values is also studied.
\end{abstract}

Keywords: FEM, Electric Field, Multi-Contaminating, Disc Spacer.

\section{Electric Field Calculations}

The computation of electric field is complex and it is usually difficult to find an exact solution. Several numerical techniques have been increasingly employed to solve such practical problems since the availability of high performance computers [1,2]. The advantage of the application of numerical methods has many advantages compared to analytical methods such as computable accuracy, simplicity and low cost.

The finite element method (FEM) is used in this paper for its favorable accuracy, when applied to high voltage problems. FEM one of the efficient technique for solving field problems is used to determine the electric field distribution on the spacer's surface. FEM concerns itself with minimization of the energy within the whole field region of interest, whether the field is electric or magnetic, of Laplacian or Poisson type, by dividing the region into triangular elements for two dimensional problems or tetrahedrons for three dimensional problems. Under steady state the electrostatic field within anisotropic dielectric material, assuming a Cartesian coordinate system, and Laplacian field, the electrical energy W stored within the whole volume $U$ of the region considered is:

$$
\begin{aligned}
& W=\frac{1}{2} \int_{U} \varepsilon|\operatorname{grad}(\boldsymbol{V})|^{2} d U \\
& W=\frac{1}{2} \iiint_{U}\left[\varepsilon_{\boldsymbol{x}}\left(\frac{\partial \boldsymbol{V}_{\boldsymbol{x}}}{\partial \boldsymbol{x}}\right)^{2}+\varepsilon_{\boldsymbol{y}}\left(\frac{\partial \boldsymbol{V}_{\boldsymbol{y}}}{\partial \boldsymbol{y}}\right)^{2}+\varepsilon_{\boldsymbol{z}}\left(\frac{\partial \boldsymbol{V}_{\boldsymbol{z}}}{\partial \mathbf{z}}\right)^{2}\right] \boldsymbol{d} \boldsymbol{x} \boldsymbol{d} \boldsymbol{d} \boldsymbol{d z}
\end{aligned}
$$

Received: June $13^{\text {rd }}$, 2013. Accepted: October $23^{\text {rd }}, 2014$ 
Furthermore, for GIS arrangement, when we consider the field behaviour at minute level the problem can be treated as two dimensional (2D). The total stored energy within this arealimited system is now given according to:

$$
\frac{W}{\varphi}=\frac{1}{2} * \varepsilon \iint\left[\left(\frac{\partial \boldsymbol{V}_{\boldsymbol{x}}}{\partial \boldsymbol{x}}\right)^{2}+\left(\frac{\partial \boldsymbol{V}_{\boldsymbol{y}}}{\partial \boldsymbol{y}}\right)^{2}\right] \boldsymbol{d x d y}
$$

where $(\mathrm{W} / \varphi)$ is thus an energy density perelementary area dA. Before applying any minimization criteria based upon the above equation, appropriate assumptions about the potential distribution $\mathrm{V}(\mathrm{x}, \mathrm{y}, \mathrm{z})$ must be made. It should be emphasized that this function is continuous and a finite number of derivatives may exist. As it will be impossible to find a continuous function for the whole area $\mathrm{A}$, an adequate discretization must be made. So all the area under consideration is subdivided into triangular elements hence:

$$
\frac{\boldsymbol{W}}{\varphi}=\frac{1}{2} * \varepsilon * \sum_{\boldsymbol{i}=1}^{\boldsymbol{n}}\left[\left(\frac{\partial \boldsymbol{V}_{\boldsymbol{x}}}{\partial \boldsymbol{x}}\right)^{2}+\left(\frac{\partial \boldsymbol{V}_{\boldsymbol{y}}}{\partial \boldsymbol{y}}\right)^{2}\right] * \boldsymbol{A}_{\boldsymbol{i}}
$$

where $\mathrm{n}$ is the total number of elements and $\mathrm{Ai}$ is the area of the ith triangle element. So the formulation regarding the minimization of the energy within the complete system may be written as:

$$
\frac{\partial \boldsymbol{X}}{\partial\{\boldsymbol{V}(\boldsymbol{x}, \boldsymbol{y})\}}=0 ; \quad \text { Where } \quad \boldsymbol{X}=\frac{\boldsymbol{w}}{\varphi}
$$

The result is an approximation for the electrostatic potential for the nodes at which the unknown potentials are to be computed. Within each element the electric field strength is considered to be constant and the electric field strength is calculated as

$$
\overrightarrow{\boldsymbol{E}}=-\overrightarrow{\boldsymbol{I}} \frac{\partial \boldsymbol{V}(\boldsymbol{x}, \boldsymbol{y})}{\partial \boldsymbol{x}}-\overrightarrow{\boldsymbol{J}} \frac{\partial \boldsymbol{V}(\boldsymbol{x}, \boldsymbol{y})}{\partial \boldsymbol{y}}
$$

The electric field is calculated with using the Finite Element Method (FEM) throughout this work. The Finite Element Method Magnetics (FEMM) Package is used to simulate the problems and to calculate the electric field inside gas insulated switchgear as discussed before in papers $[3,4,5,6]$ and gas insulated bus ducts as disscussed in this paper with various spacers. FEMM is a finite element package for solving 2D planar and axi-symmetric problems in electrostatics and in low frequency magnetic [7].

\section{Modeling of Gas Insulated Bus Duct}

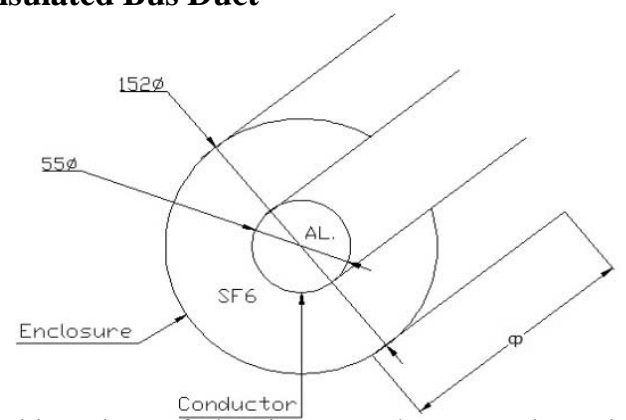

Figure 1. Gas insulated bus duct of aluminum enclosure and conductor with diameters 152 , $55 \mathrm{~mm}$ respectively 
Gas insulated bus duct with aluminum enclosure and aluminum conductor is modeled as shown in Figure 1 in a two dimensional axis. Diameters of the enclosure and conductor are $152 \mathrm{~mm}, 55 \mathrm{~mm}$ respectively. The void is been filled with $\mathrm{SF}_{6}$ gas. The analysis is done by using two concentric cylinder of infinite length as shown in Figure 1. The voltage on the inner conductor of GIBD considered is taken as 1V, For any applied voltage the values of the electric fields can be proportioned.

\section{A. Electrostatic modeling of GIBD with particle contamination}

Figure 2 shows Gas insulated bus duct with filamentary wire contaminating particle resting on earthed enclosure. The gap between conductor and enclosure is filled with $\mathrm{SF}_{6}$ gas. In this figure, $\mathrm{L}$ is defined as particle length, $\mathrm{r}$ is defined as hemispherical radius of particle and $\mathrm{Gu}$ is the upper gap space from upper tip of earthed wire particle up to inner conductor.

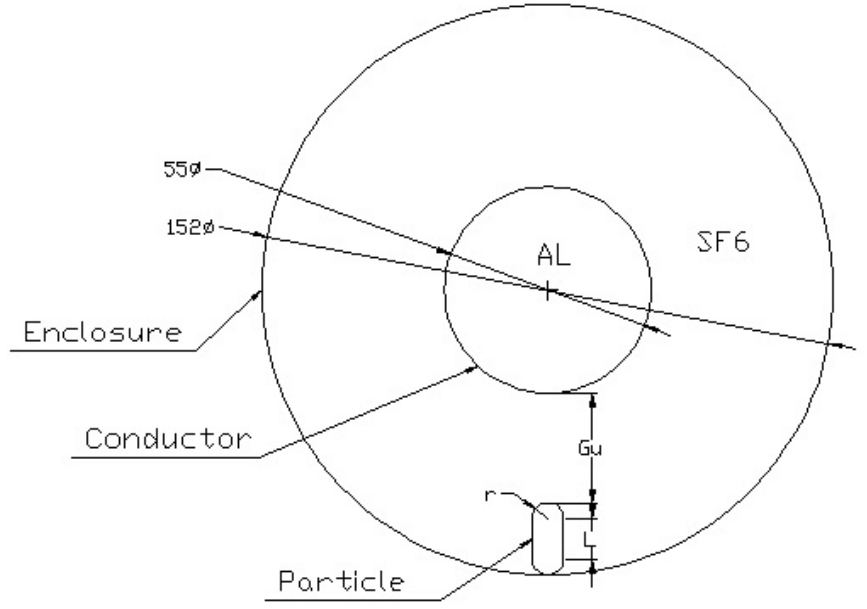

Figure 2. Gas insulated bus duct with filamentary wire contaminating particle resting on earthed enclosure

(a) For wire particle of $10 \mathrm{~mm}$ length and of $0.5 \mathrm{~mm}$ radius

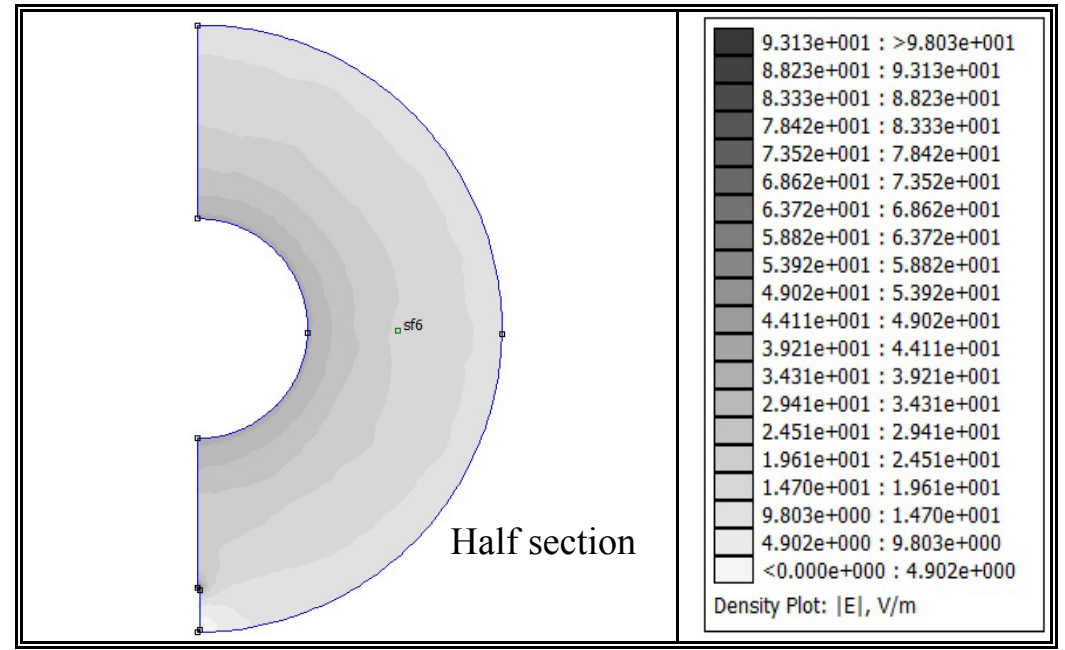

Figure 3. Electric field distribution along gap inside gas insulated bus duct with wire contaminating particle resting on earthed enclosure 
Figure 3 shows the electric field distribution along gap inside gas insulated bus duct with wire contaminating particle resting on earthed enclosure. It can be observed that the electric field is minimum value at lower tip of particle and maximum value at upper tip of it and also the electric field decreases from upper tip of wire particle till reaches a certain value but after this value, it returns to increase till reaches to a certain value $36 \mathrm{~V} / \mathrm{m}$ at inner conductor of gas insulated bus duct.

Figure 4 shows magnitude, normal and tangential components of electric field distribution along surface of wire particle. It can be observed that the tangential component of electric field is zero and the normal component of it increases gradually from zero until it reaches maximum value at upper tip through negative side, so mathematically ,the magnitude of electric field increases also from zero to $97.5 \mathrm{~V} / \mathrm{m}$ at upper tip of wire particle though positive side .

Figure 5 shows magnitude, normal and tangential components of electric field distribution along gap from upper tip of wire particle up to inner conductor of GIBD. It can be observed that normal component of electric field is zero. The tangential component of electric field is maximum value $(\approx 97.5 \mathrm{~V} / \mathrm{m})$ at upper tip of wire particle and decreases gradually along gap until it reaches $13 \mathrm{~mm}$ from tip but after $13 \mathrm{~mm}$ from tip up to inner conductor, the electric field increases gradually until it reaches a certain value is about $36 \mathrm{~V} / \mathrm{m}$.

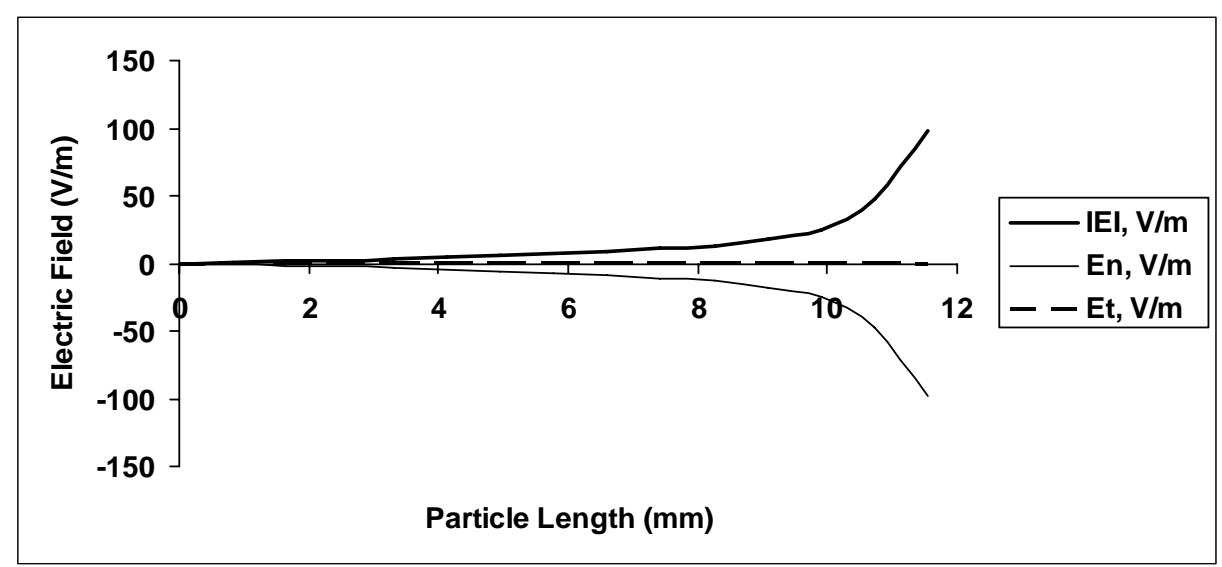

Figure 4. Electric field distribution along surface of wire particle

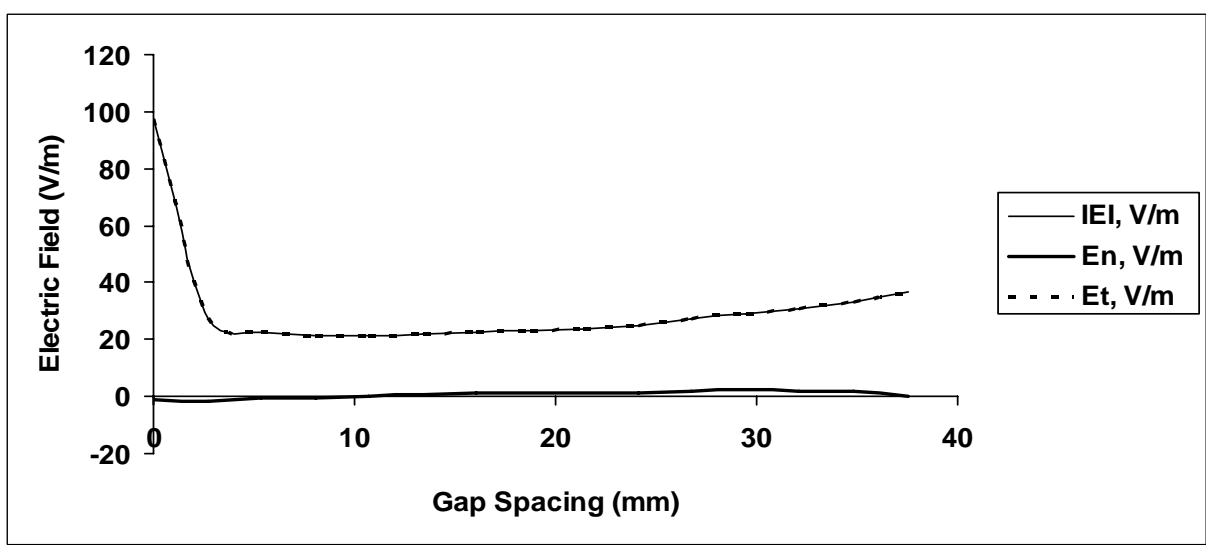

Figure 5. Electric field distribution along gap from upper tip of wire particle up to inner conductor of GIBD 
(b) Effect of particle length on the electric field values

The variation of the electric field values at the upper tip of the wire particle with respect to the particle length at $(\mathrm{r}=0.5 \mathrm{~mm})$ is shown in Figure6. It can be observed that as the particle length increases, the maximum electric field at upper tip of wire particle increases also.

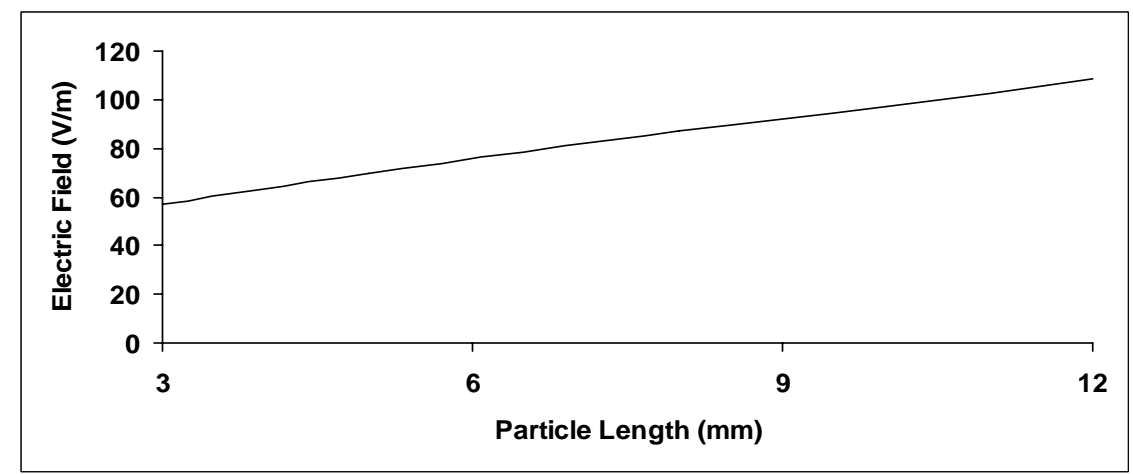

Figure 6. Electric Field at upper tip of wire particle versus Particle length at $r=0.5 \mathrm{~mm}$

(c) Effect of particle radius on the electric field

The effect of changing the wire particle radius on the electric field values at the upper tip of the wire particle is shown in Figure7. The wire particle length is taken as $10 \mathrm{~mm}$. As the wire particle radius increases from $0.5 \mathrm{~mm}$ to $1 \mathrm{~mm}$, the maximum electric field at upper tip of the wire particle decreases gradually from about $97.5 \mathrm{~V} / \mathrm{m}$ to about $76.3 \mathrm{~V} / \mathrm{m}$, i.e as the wire particle radius increases, the electric field decreases.

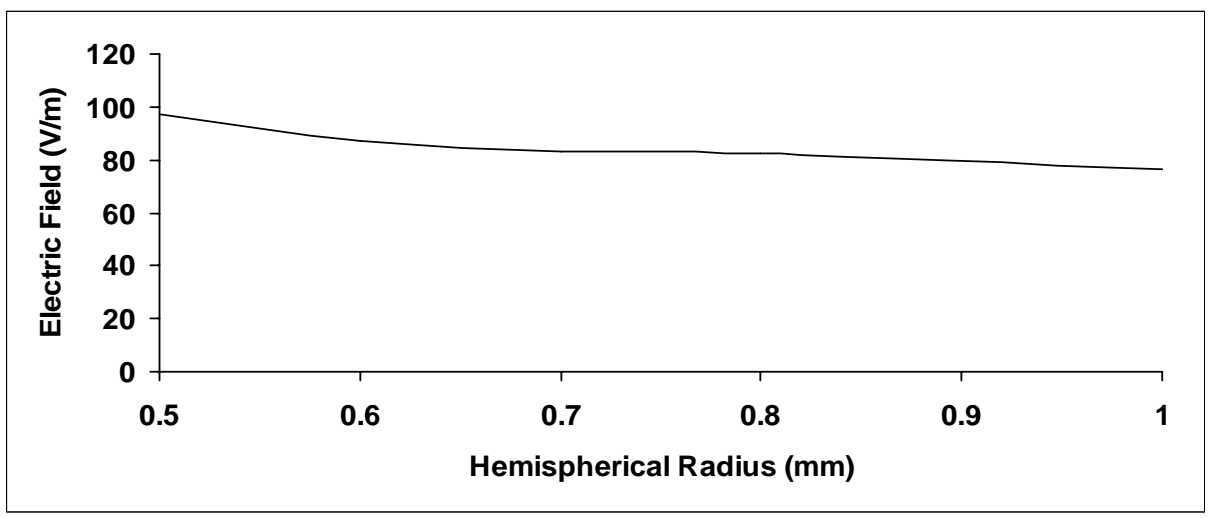

Figure 7. Electric Field at upper tip of wire particle versus particle radius at $\mathrm{L}=10 \mathrm{~mm}$

\section{(d) Effect of Ratio (L/r) on the electric field}

Figure 8 shows the variation of the electric field values at the upper tip of the wire particle with respect to the ratio $(\mathrm{L} / \mathrm{r})$ at $(\mathrm{r}=0.5 \mathrm{~mm})$. It can be observed that as the ratio of $(\mathrm{L} / \mathrm{r})$ increases from 6 to 24 , the electric field at upper tip of the wire particle will increase from about $56.8 \mathrm{~V} / \mathrm{m}$ to about $108.8 \mathrm{~V} / \mathrm{m}$. 
Mousa A. Abd-Allah, et al.

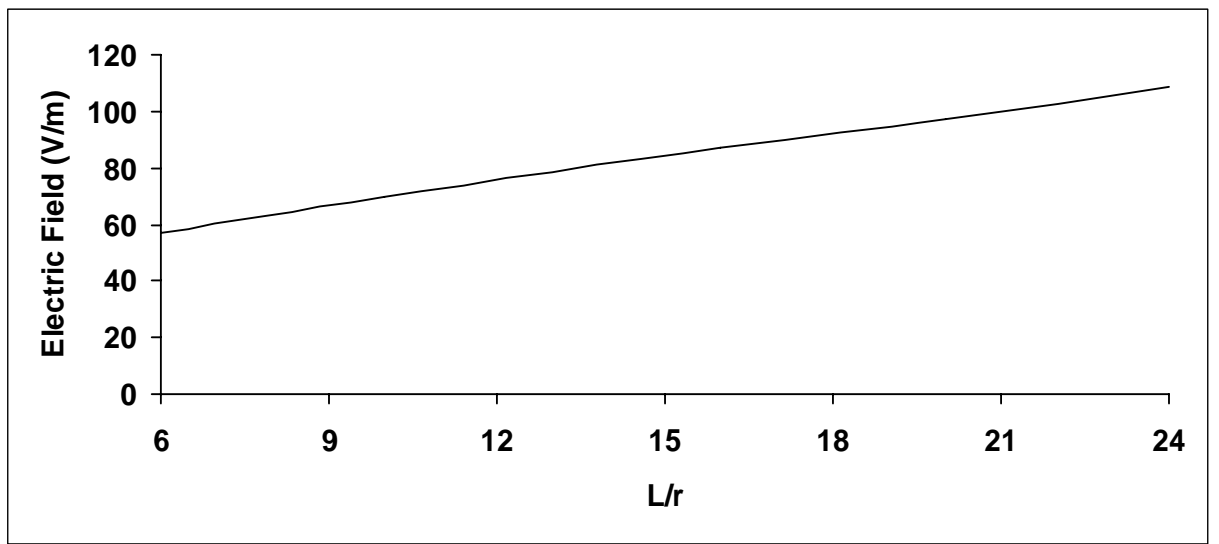

Figure 8. Electric Field at upper tip of wire particle as a function of the ratio $(\mathrm{L} / \mathrm{r})$ at $\mathrm{r}=0.5 \mathrm{~mm}$

B. Electrostatic modeling of GIBD with particle contamination and dielectric coating of enclosure

The purpose of coating the inside surface of gas insulated bus duct (GIBD) enclosure with a dielectric material reduces the deleterious effect of electrode surface roughness, increases the field required to lift particles, and reduces the charge acquired by particles. The electric field necessary to lift a particle resting on the inside surface of a GIBD enclosure is increased due to the coating. Once a particle begins to move in the gas gap under the applied voltage, it may collide with either conductor. With coated conductors the particle will acquire a drastically reduced charge, thus the risk of breakdown initiated by a discharge is reduced significantly [8].

Figure 9 shows Gas insulated bus duct with filamentary wire contaminating particle in contact with dielectric coating of earthed enclosure. In this figure, $(t)$ is defined as dielectric coating thickness and it varies from 200micro-meter to 2000micro-meter. The dielectric material of coating can be epoxy, varnish or polymeric films.

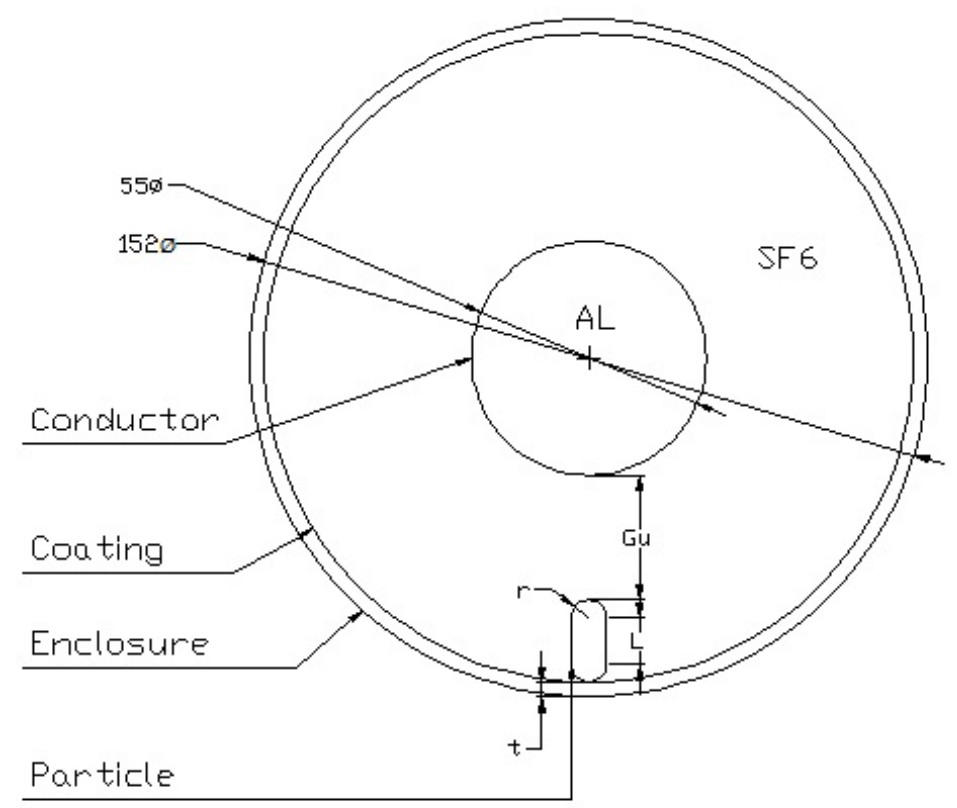

Figure 9. Gas insulated bus duct with filamentary wire contaminating particle in contact with dielectric coating of earthed enclosure 
(a) When dielectric coating of earthed enclosure of 2000micro-meter thickness

The particle dimensions are taken as $10 \mathrm{~mm}$ length and $0.5 \mathrm{~mm}$ radius. The thickness of dielectric coating for earthed enclosure is taken as 2000 micro-meter and epoxy material of relative permittivity $(\mathrm{er}=4.5)$ is used for coating. The voltage decreases gradually from 1 volt at inner conductor through the gap until it reaches zero at the grounded enclosure.

Figure 10 shows the electric field distribution along gap inside gas insulated bus duct with wire contaminating particle in contact with dielectric coating of earthed enclosure. It can be observed that the electric field is minimum value at lower tip of particle and maximum value at upper tip of it and also the electric field decreases from upper tip of wire particle till reaches a certain value but after this value, it returns to increase till reaches to a certain value $36 \mathrm{~V} / \mathrm{m}$ at inner conductor of gas insulated bus duct.

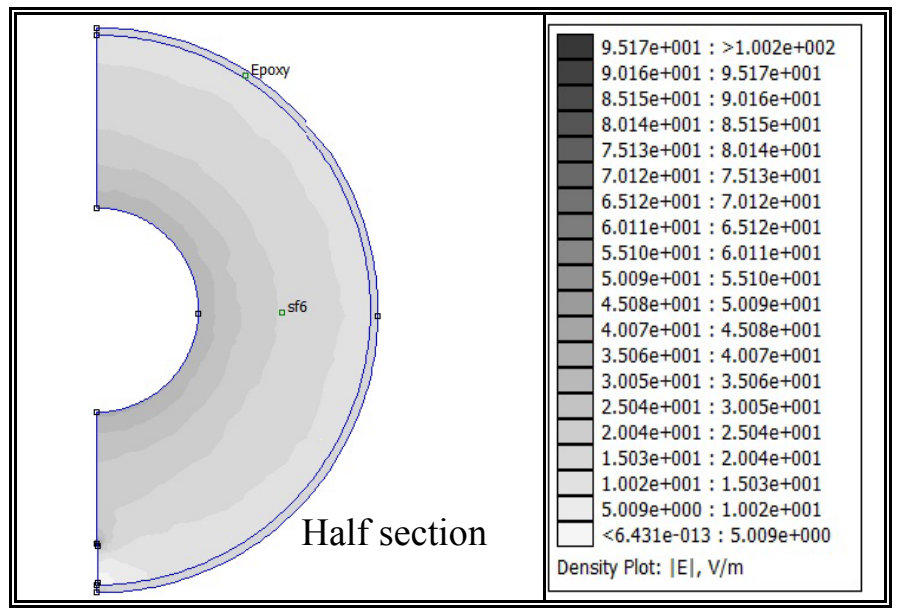

Figure 10. Electric field distribution along gap inside gas insulated bus duct with wire contaminating particle in contact with dielectric coating of earthed enclosure

Figure 11 shows magnitude, normal and tangential components of electric field distribution along surface of wire particle. It can be observed that the tangential component of electric field is zero and the normal component of it increases gradually from zero until reach to maximum value at upper tip through negative side, so mathematically, the magnitude of electric field increases also from zero to $99.6 \mathrm{~V} / \mathrm{m}$ at upper tip of wire particle though positive side.

Figure 12 shows magnitude, normal and tangential components of electric field distribution along gap from upper tip of wire particle up to inner conductor of GIBD. It can be observed that normal component of electric field is zero. The tangential component of electric field is maximum value $(\approx 99.6 \mathrm{~V} / \mathrm{m})$ at upper tip of wire particle and decreases gradually along gap until it reaches $7.8 \mathrm{~mm}$ from tip but after $7.8 \mathrm{~mm}$ from tip up to inner conductor, the electric field increases gradually until it reaches a certain value is about $36 \mathrm{~V} / \mathrm{m}$.

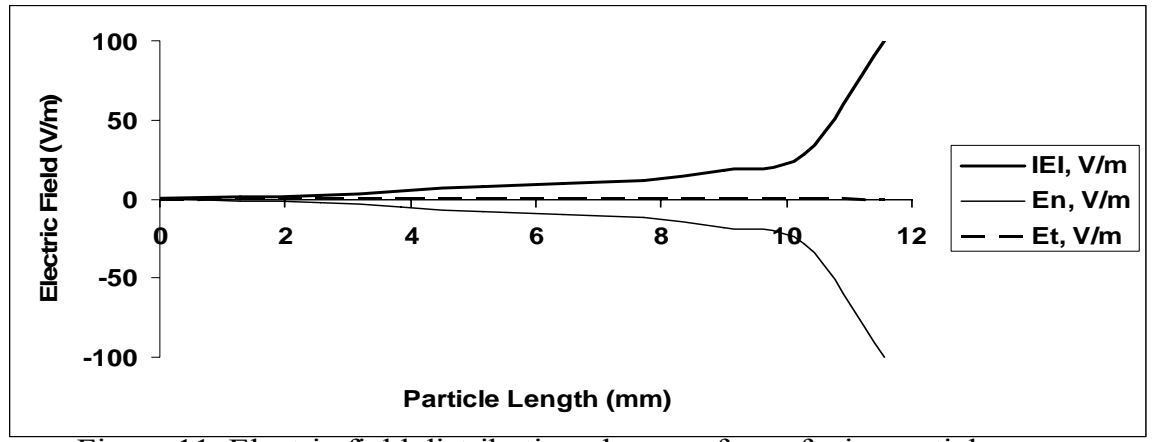

Figure 11. Electric field distribution along surface of wire particle 
Mousa A. Abd-Allah, et al.

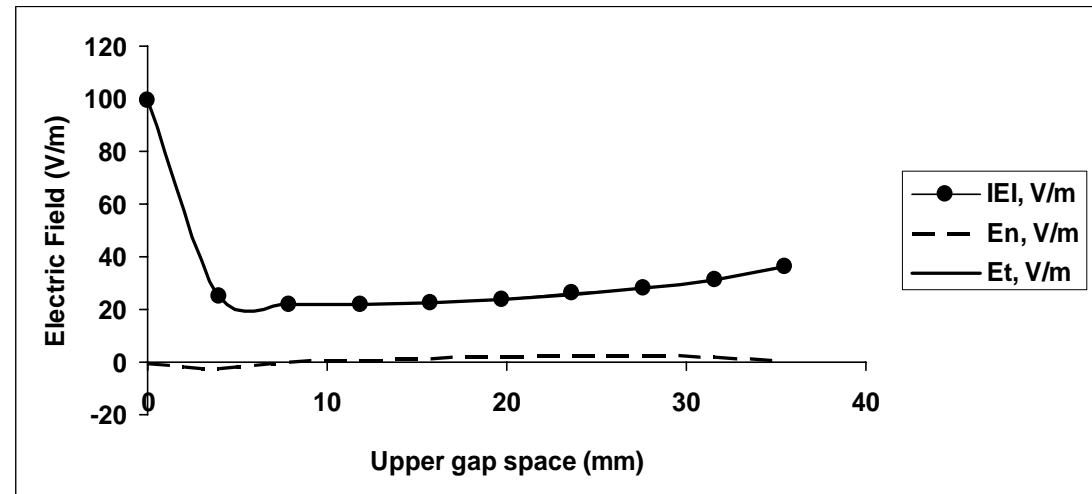

Figure 12. Electric field distribution along gap from upper tip of wireparticle up to inner conductor of GIBD

(b) Effect of coating thickness on maximum electric field

Table 1 and table 2 show maximum values of electric field at upper tip of wire particle versus various values of coating thickness of earthed enclosure of gas insulated bus duct with different dielectric materials of coating such as epoxy and varnish as shown on the tables. From these tables, it can be observed that there is a very small effect on the electric field values at upper tip of earthed wire particle whether without coating or with coating and also the variation of coating thickness from 0 to 2000 micro-meter has a small effect on the electric field values at upper tip of earthed wire particle.

Table 1. Maximum values of electric field versus coating thickness of epoxy material

\begin{tabular}{|c|c|c|}
\hline Coating thickness, $\boldsymbol{\mu m}$ & Emax, $\mathbf{V} / \mathbf{m}$ & Coating material \\
\hline 0 & 97.8474055 & Without coating \\
\hline 200 & 97.8585261 & \\
\hline 500 & 98.2674681 & \multirow{2}{*}{ Epoxy coating } \\
\hline 1000 & 98.6685527 & \\
\hline 1500 & 99.0728955 & \\
\hline 2000 & 99.6358183 & \\
\hline
\end{tabular}

Table 2. Maximum values of electric field versus coating thickness of varnish material

\begin{tabular}{|c|c|c|}
\hline Coating thickness, $\boldsymbol{\mu m}$ & Emax, V/m & Coating material \\
\hline 0 & 97.8474055 & Without coating \\
\hline 200 & 97.8585261 & \\
\hline 500 & 98.2674681 & \multirow{2}{*}{ Varnish coating } \\
\hline 1000 & 98.6685526 & \\
\hline 1500 & 99.0729002 & \\
\hline 2000 & 99.6358153 & \\
\hline & & \\
\hline
\end{tabular}

C. Electrostatic modeling of GIBD with Multi-contaminating fixed particles rested on the ground enclosure

A study of CIGRE group suggests that $20 \%$ of failure in GIS is due to the existence of various metallic contaminations in the form of loose particles. So, in this paper, we study the effect of multi-wire particles on the electric field. 
Figure 13 shows Gas insulated bus duct with multi-wire contaminating fixed particles in contact with dielectric coating of earthed enclosure. The three wire contaminating particles are identical in length and radius. Consider that the middle particle length (L1) is taken as $5 \mathrm{~mm}$, outermost particles (L2) as $5 \mathrm{~mm}$ and hemi-spherical radius of particles (r) are taken as $0.5 \mathrm{~mm}$. The spacing between middle particle and outermost particles is taken as $15 \mathrm{~mm}$. Gu1 is defined as upper gap space from upper tip of middle particle up to high voltage conductor and Gu2 is defined as upper gap space from upper tip of outermost particles up to high voltage conductor.

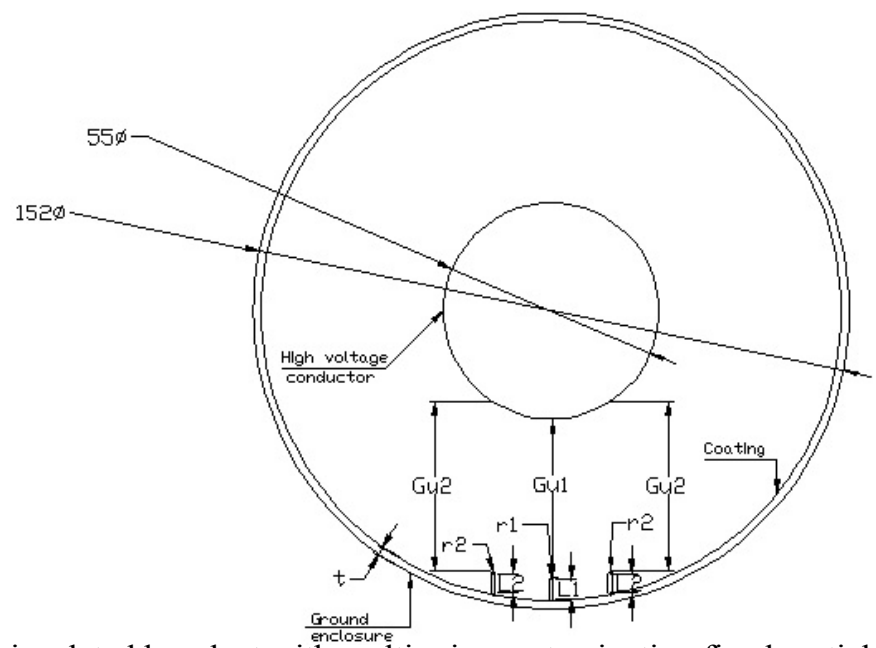

Figure 13. Gas insulated bus duct with multi-wire contaminating fixed particles in contact with dielectric coating of earthed enclosure

(a) For wire particle of $5 \mathrm{~mm}$ length and of $0.5 \mathrm{~mm}$ radius

The potential distribution along gap between inner conductor and earthed enclosure of gas insulated bus duct with multi-wire contaminating particles, resting on earthed enclosure is shown in Figure 14.

It can be observed that the voltage decreases gradually from 1volt at inner conductor through the gap until it reaches zero at the grounded enclosure.

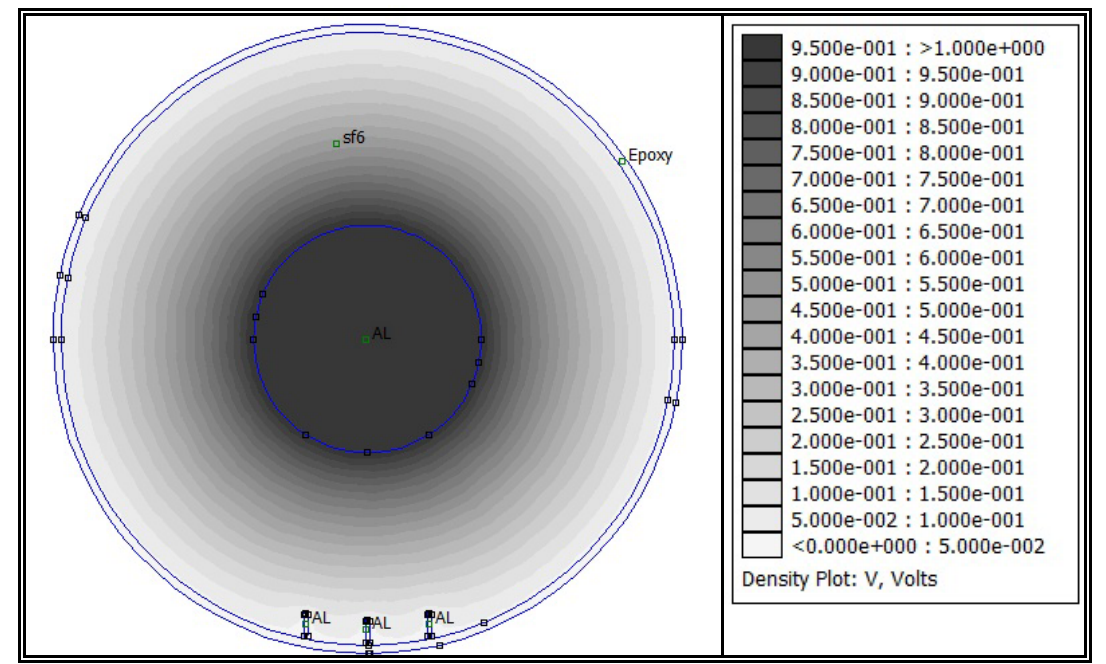

Figure 14. Potential distribution along gap inside gas insulated bus duct with multi-wire contaminating particles resting on earthed enclosure 


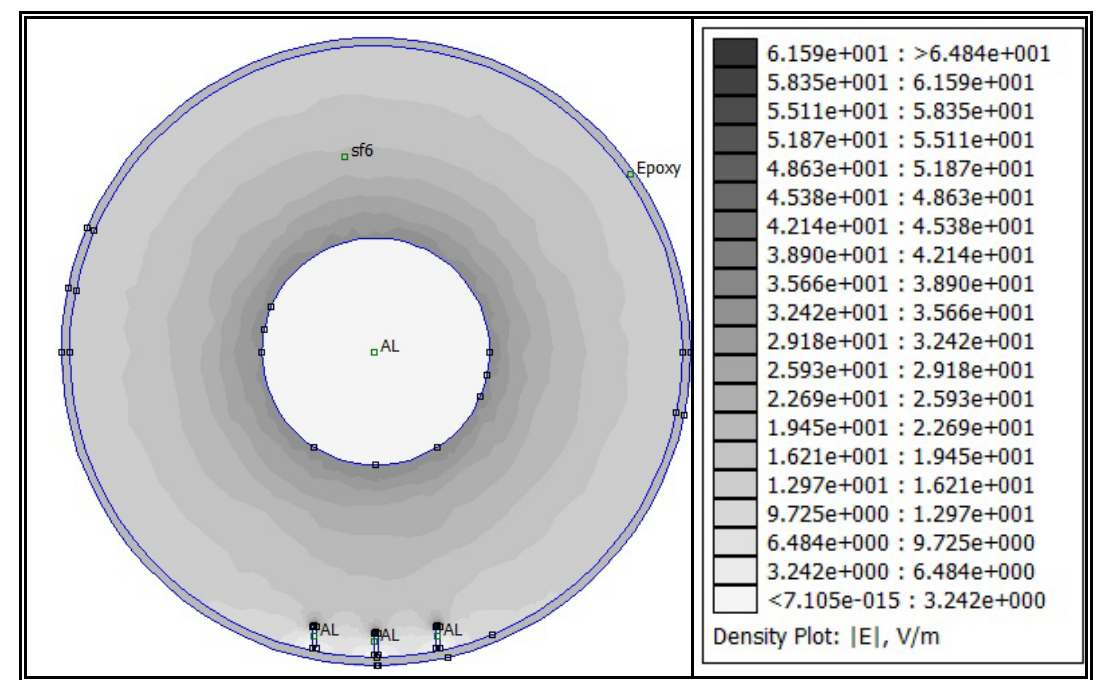

Figure 15. Electric field distribution along gap inside gas insulated bus duct with multi-wire contaminating particles resting on earthed enclosure

Figure 15 shows the electric field distribution along gap inside gas insulated bus duct with multi-wire contaminating particles resting on earthed enclosure. It can be observed that the electric field is minimum value at lower tip of middle and outermost particles and maximum value at upper tip of it but the maximum value of electric field at upper tip of outermost particles are slight increased from that at upper tip of middle particle. The electric field decreases from upper tip of wire particle till reaches a certain value but after this value, it returns to increase till reaches to the maximum value of electric field at inner conductor of GIBD in case of clean gap without any particle contamination.

Figure 16 \& Figure 17 show magnitude, normal and tangential components of electric field distribution along surface of middle and outermost particles respectively. It can be observed that the tangential component of electric field is zero and the normal component of it increases gradually from zero until it reaches maximum value at upper tip through negative side, so mathematically, the magnitude of electric field increases also from zero to $60.14 \mathrm{~V} / \mathrm{m}$ and to $62.6 \mathrm{~V} / \mathrm{m}$ at upper tip of middle and outermost particles respectively through positive side.

Figure 18 shows electric field distribution along surface of middle and outermost particles. It can be observed that the electric field at upper tip of outermost particles is slightly greater than it at upper tip of middle particle and this is because the outermost particles which rested at ground enclosure is nearer to high voltage conductor than middle particle.

Figure 19 \& Figure 20 show magnitude, normal and tangential components of electric field distribution along gap from upper tip of middle and outermost particles up to high voltage conductor. It can be observed that normal component of electric field is about zero and the tangential component of it decreases gradually from maximum value at upper tip of particle until it reaches a certain value but after that value, it returns to increase through negative side, so mathematically, the magnitude of electric field decreases gradually from $60.14 \mathrm{~V} / \mathrm{m}$ and $62.6 \mathrm{~V} / \mathrm{m}$ at upper tip of middle and outermost particles respectively until it reaches a certain value but after that value, it returns to increase as it approaches from high voltage conductor through positive side. 


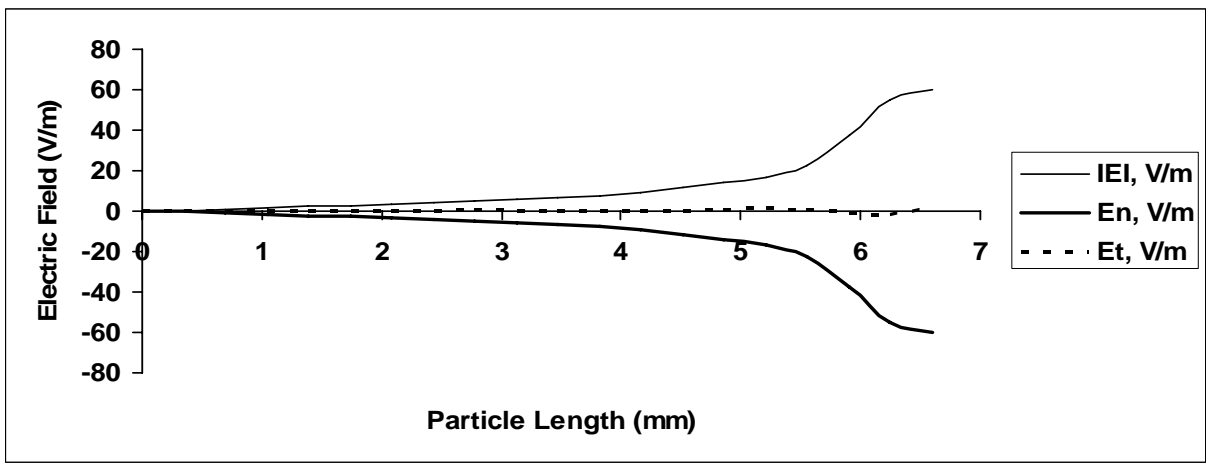

Figure 16. Electric field distribution along surface of middle particle

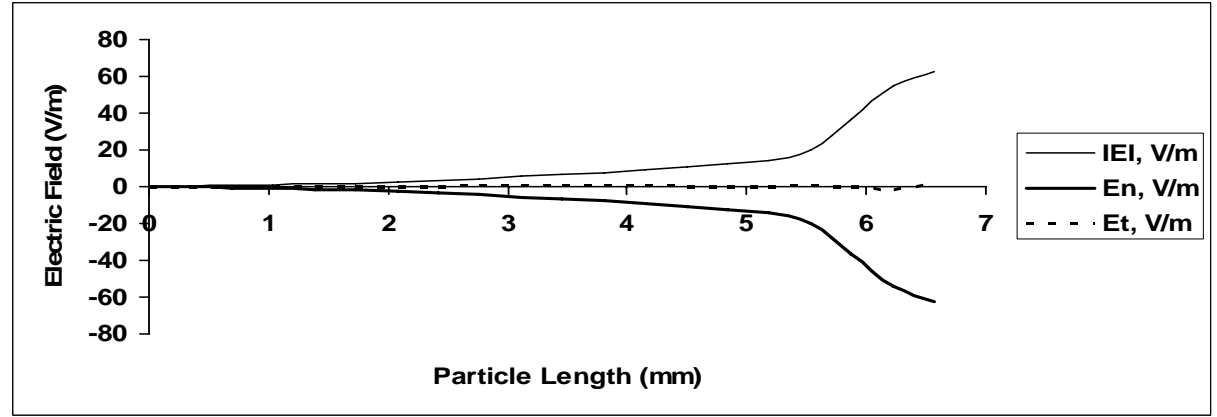

Figure 17. Electric field distribution along surface of outermost particles

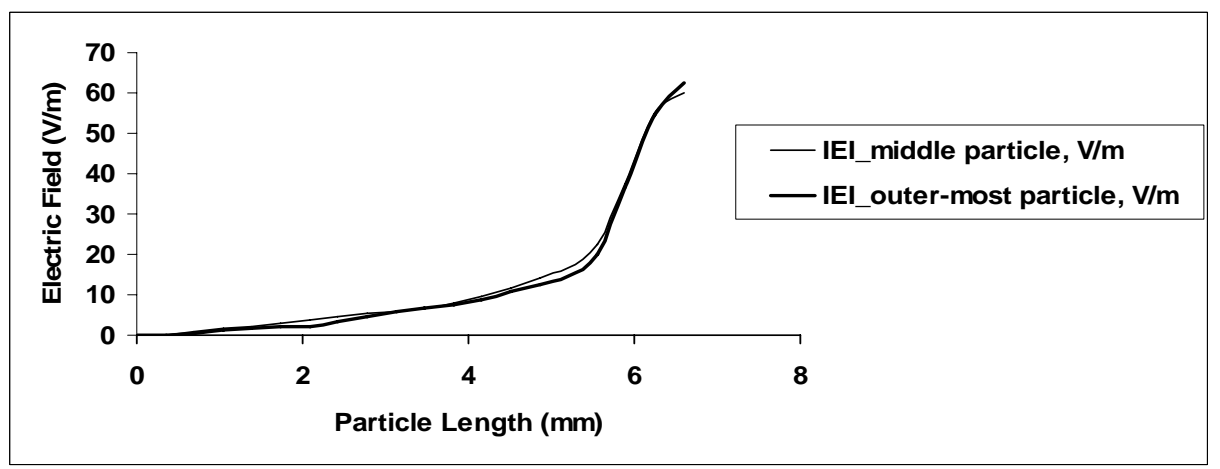

Figure 18. Electric field distribution along surface of middle and outermost particles

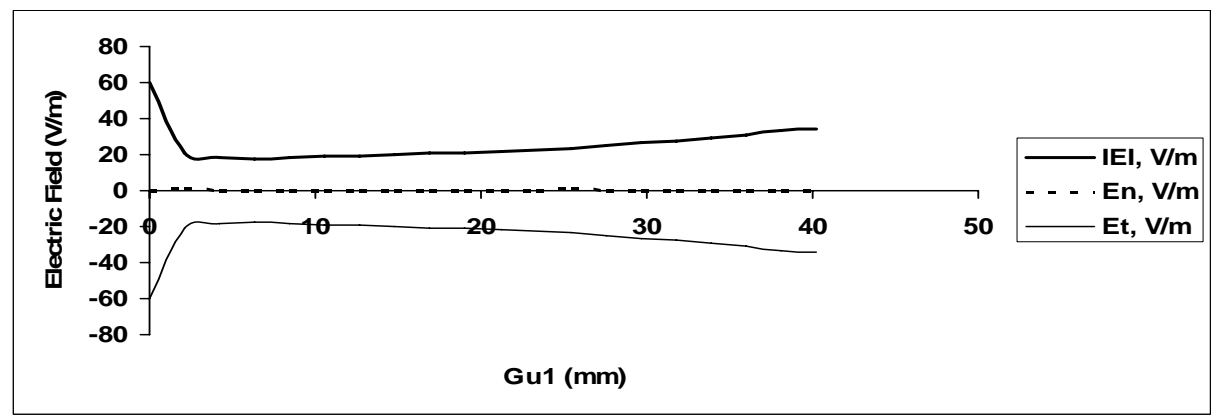

Figure 19. Electric field distribution along gap from upper tip of middle particle up to high voltage conductor 
Mousa A. Abd-Allah, et al.

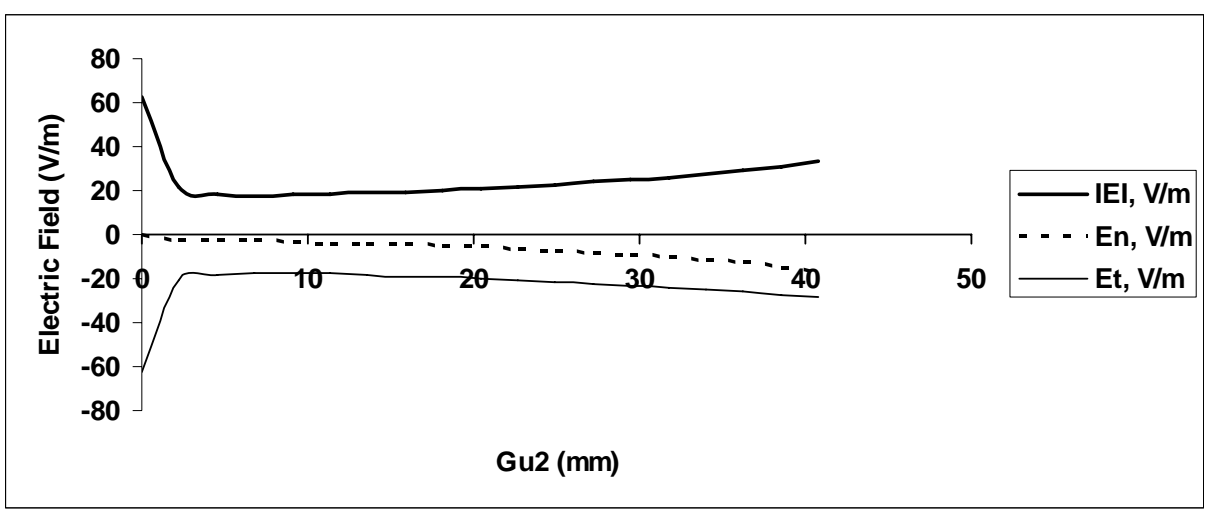

Figure 20. Electric field distribution along gap from upper tip of outermost particles up to high voltage conductor

(b) Effect of changing the particle length of middle particle on the electric field values

The variation of the electric field values at the upper tip of middle and outermost fixed particles with respect to the particles lengths at $(\mathrm{r} 1, \mathrm{r} 2=0.5 \mathrm{~mm})$ is shown in Figure 21 . When the dimensions of outermost particles are constant at $5 \mathrm{~mm}$ length and $0.5 \mathrm{~mm}$ hemispherical radius and change the length of middle fixed particle from $3 \mathrm{~mm}$ to $12 \mathrm{~mm}$ at constant $0.5 \mathrm{~mm}$ radius, it can be observed that as length of middle fixed particle increases at constant length of outermost particles, the maximum electric field at upper tip of middle particle increases also but it slightly decreased at upper tip of outermost particles.

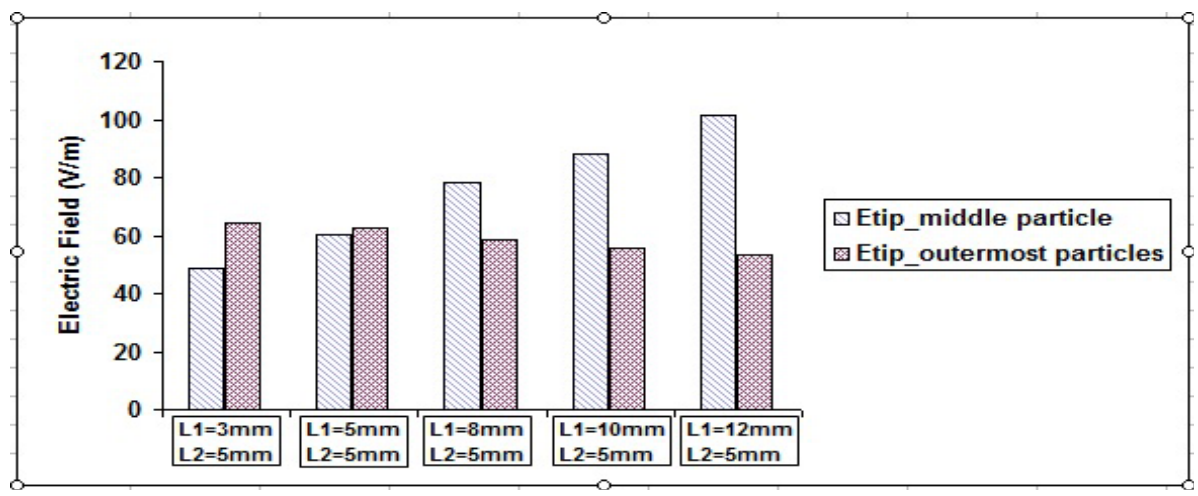

Figure 21. Electric Field at upper tip of wire particles versus Particles lengths at $r=0.5 \mathrm{~mm}$

(c). Effect of changing the particle radius of middle particle on the electric field values

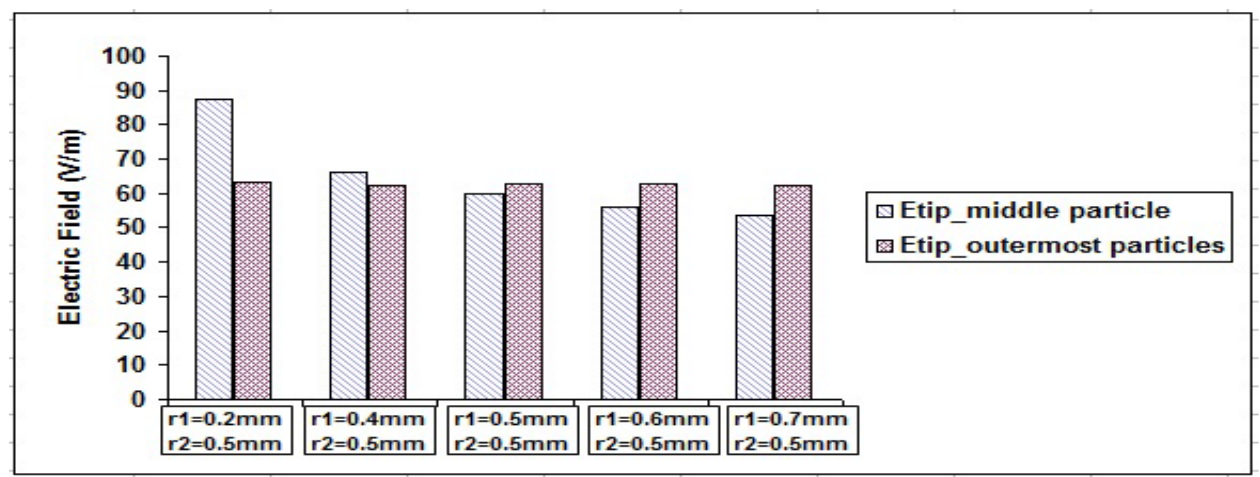

Figure 22. Electric Field at upper tip of wire particles versus Particles radius at $\mathrm{L}=5 \mathrm{~mm}$ 
The variation of the electric field values at the upper tip of middle and outermost fixed particles with respect to the particles radius at $(\mathrm{L} 1, \mathrm{~L} 2=5 \mathrm{~mm})$ is shown in Figure 22. When the dimensions of outermost particles are constant at $5 \mathrm{~mm}$ length and $0.5 \mathrm{~mm}$ hemispherical radius and change the radius of middle fixed particle from $0.2 \mathrm{~mm}$ to $0.7 \mathrm{~mm}$ at constant $5 \mathrm{~mm}$ length, it can be observed that as radius of middle fixed particle increases at constant radius of outermost particles, the maximum electric field at upper tip of middle particle decreases and this means that the electric field is maximum at thin particles but it still approximately constant at upper tip of outermost particles.

\section{Electric field distribution around Disc-spacer}

Gas insulated bus duct consists of aluminum conductor is supported by disc-spacer with the aluminum enclosure as shown in the Figure 23. All dimensions of gas insulated bus duct with coating and disc-spacer are given in millimeter as shown in the figure. Disc-spacer is made of epoxy material with width $30 \mathrm{~mm}$ and relative permativity ( $\mathrm{\epsilon r}=4.5)$.

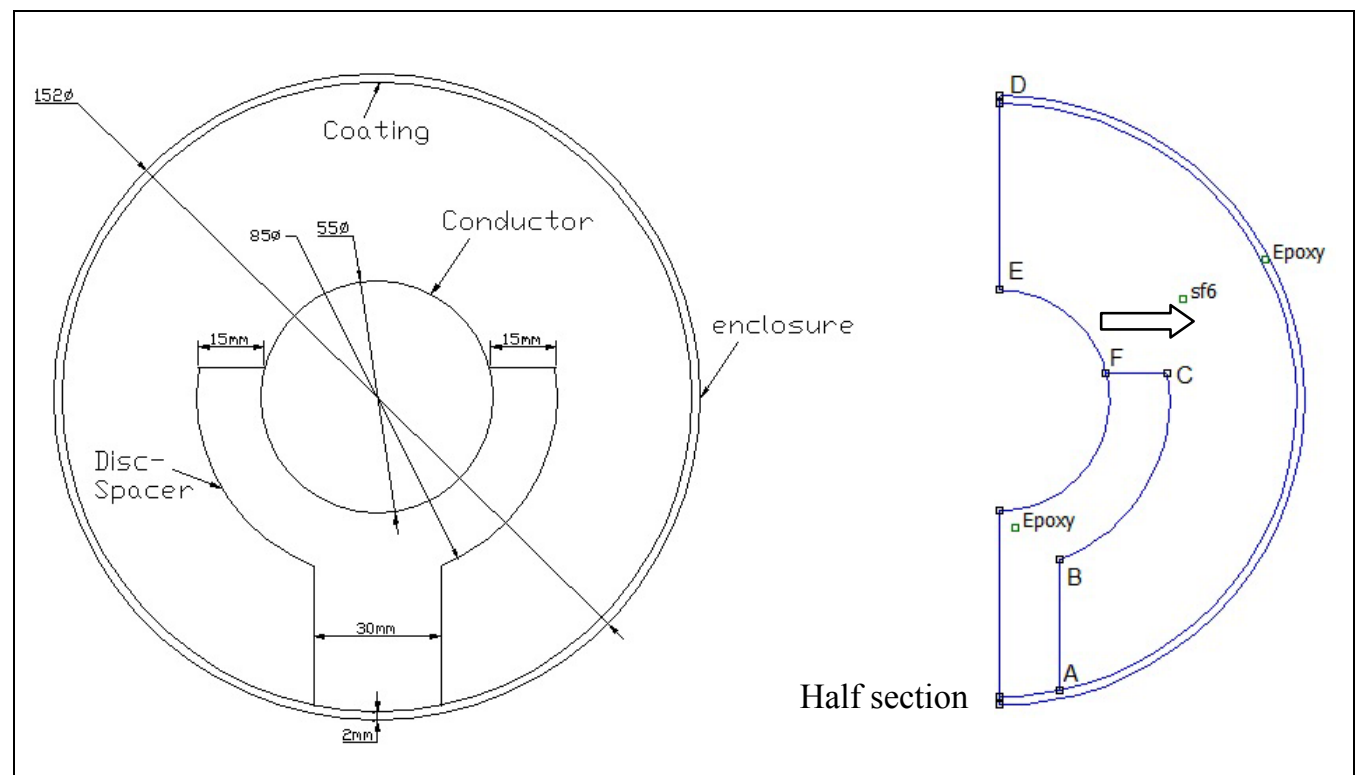

Figure 23. Gas insulated bus duct with disc-spacer of epoxy material and with 30mm width

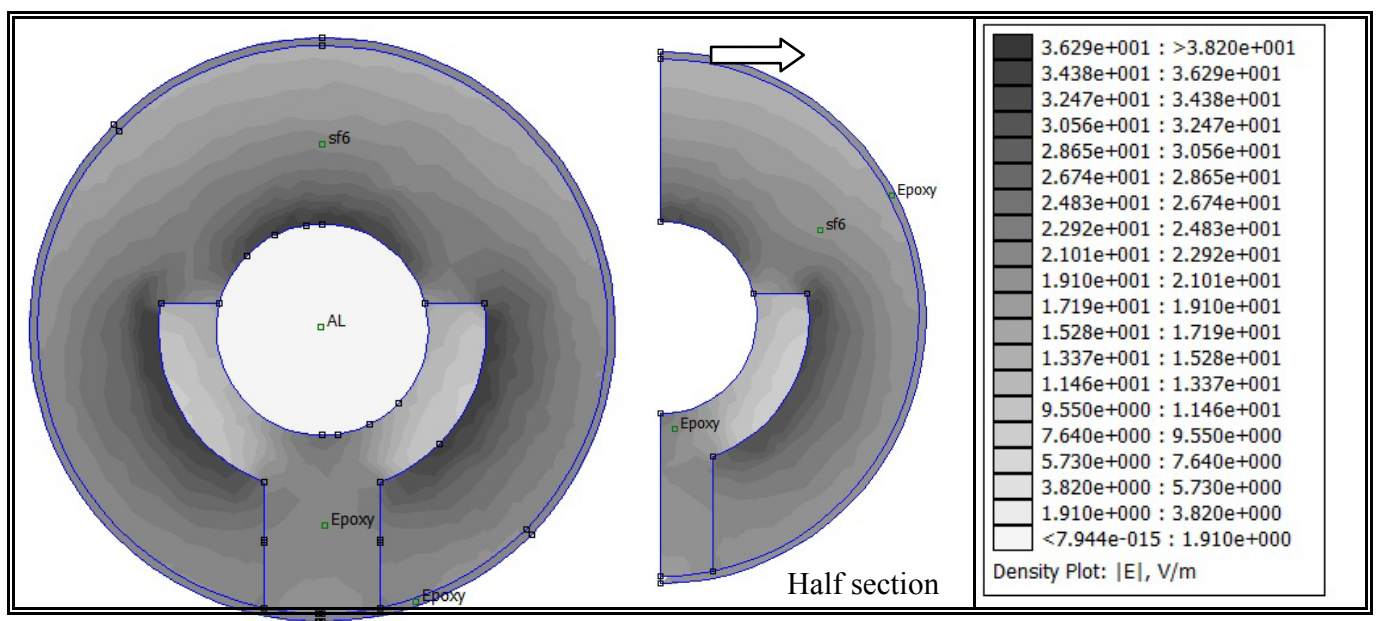

Figure 24. Electric field distribution along surface of disc-spacer inside gas insulated bus duct 
Figure 24 shows the electric field distribution along surface of disc-spacer inside gas insulated bus duct. From the side of $\mathrm{SF}_{6}$ gas, it can be observed that the electric field along disc-spacer increases from point $\mathrm{A}$ to point $\mathrm{B}$ and after this point, it becomes approximately constant from point $\mathrm{B}$ to point $\mathrm{C}$ but it decreases from point $\mathrm{C}$ until it reaches triple junction point $\mathrm{F}$. From the side of Epoxy material of spacer, it can be observed that the electric field along surface of disc-spacer is slightly increased from point $\mathrm{A}$ to point $\mathrm{B}$ and after that point, the electric field decreases gradually until it reaches constant value along $\mathrm{BC}$ path but it slightly increased from point $C$ until it reaches triple junction point $F$.

Figure 25 shows magnitude, normal and tangential components of electric field distribution along surface of disc-spacer from $\mathrm{SF}_{6}$ gas side inside gas insulated bus duct. It can be observed that normal component of electric field increases gradually from $5 \mathrm{~V} / \mathrm{m}$ at point $\mathrm{A}$ until it reaches about $33 \mathrm{~V} / \mathrm{m}$ at point $\mathrm{B}$ and it's approximately constant along spacer surface from point $B$ to point $C$ but it decreases gradually from about $33 \mathrm{~V} / \mathrm{m}$ at point $C$ until it reaches $4 \mathrm{~V} / \mathrm{m}$ at triple junction point $\mathrm{F}$. The tangential component of electric field increases gradually from point $\mathrm{A}$ to point $\mathrm{B}$ but after this point, it decreases gradually until it reaches point $\mathrm{C}$ and then it increased from point $\mathrm{C}$ until it reaches $14 \mathrm{~V} / \mathrm{m}$ at triple junction point $\mathrm{F}$. Finally, total component of electric field increases gradually from about $20 \mathrm{~V} / \mathrm{m}$ at point $\mathrm{A}$ until it reaches $33 \mathrm{~V} / \mathrm{m}$ at point $\mathrm{B}$ and it's approximately constant along spacer surface from point $\mathrm{B}$ to point $\mathrm{C}$ but it decreases gradually from about $33 \mathrm{~V} / \mathrm{m}$ at point $\mathrm{C}$ until it reaches $14 \mathrm{~V} / \mathrm{m}$ at point $\mathrm{F}$.

Figure 26 shows magnitude, normal and tangential components of electric field distribution along surface of disc-spacer from Epoxy side inside gas insulated bus duct. It can be observed that normal component of electric field is slightly increased from point A until it reaches point $\mathrm{B}$ and after this point, it decreases and then it becomes constant along $\mathrm{BC}$ path but it returns to increase from point $\mathrm{C}$ until it reaches triple junction point $\mathrm{F}$. The tangential component of electric field increases from point $\mathrm{A}$ to point $\mathrm{B}$ at the negative side until it reaches zero and after this point, it varies around zero until it reaches point $\mathrm{C}$ but it decreases when it approached from triple junction point F. Finally, total component of electric field is slightly increased from point $\mathrm{A}$ until it reaches point $\mathrm{B}$ and after this point, it decreases and becomes approximately constant along arc surface of spacer until it reaches point $\mathrm{C}$ and it becomes approximately constant from point $\mathrm{C}$ to point $\mathrm{F}$ of triple junction.

Figure 27 shows magnitude, normal and tangential components of electric field distribution along gap (DEF path ) inside gas insulated bus duct. It can be observed that normal component of electric field is around zero from point $\mathrm{D}$ to point $\mathrm{E}$ and after this point, it increases and then it decreases gradually until it reaches triple junction point $\mathrm{F}$. The tangential component of electric field decreases gradually from point $\mathrm{D}$ to point $\mathrm{E}$ at the negative side and after this point, it increases until it reaches zero and it still constant (Zero) along conductor surface from point $\mathrm{E}$ to point $\mathrm{F}$. Finally, total component of electric field increases gradually from $13 \mathrm{~V} / \mathrm{m}$ at point $\mathrm{D}$ until it reaches $36 \mathrm{~V} / \mathrm{m}$ at point $\mathrm{E}$ but it decreases from $36 \mathrm{~V} / \mathrm{m}$ at point $\mathrm{E}$ until it reaches $14 \mathrm{~V} / \mathrm{m}$ at triple junction point $\mathrm{F}$ along conductor surface.

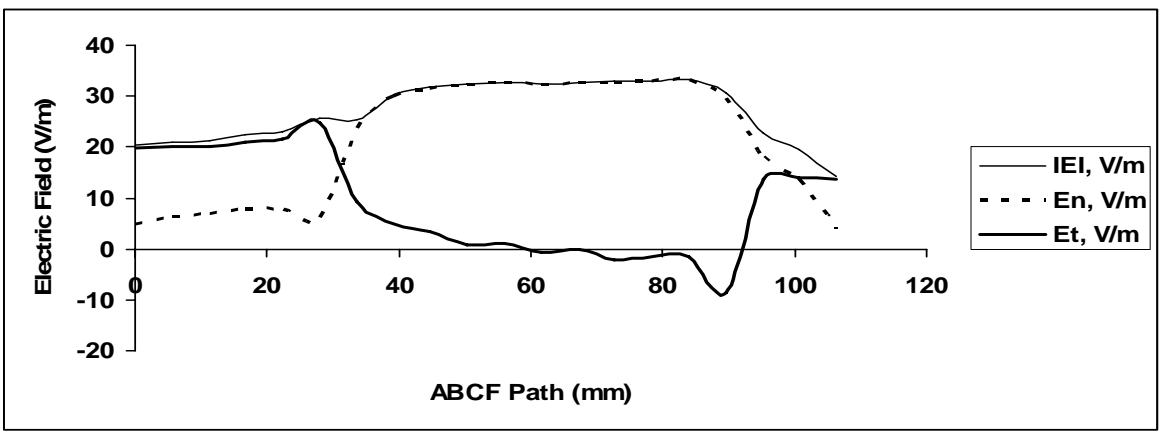

Figure 25. Electric field distribution along surface of disc-spacer from $\mathrm{SF}_{6}$ gas side inside gas insulated bus duct 


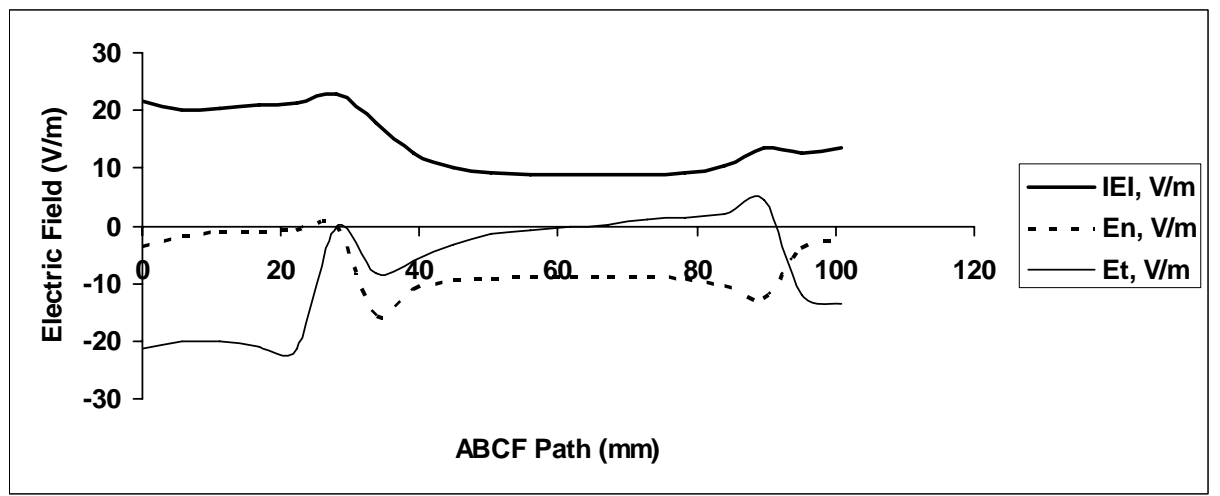

Figure 26. Electric field distribution along surface of disc-spacer from Epoxy side inside gas insulated bus duct

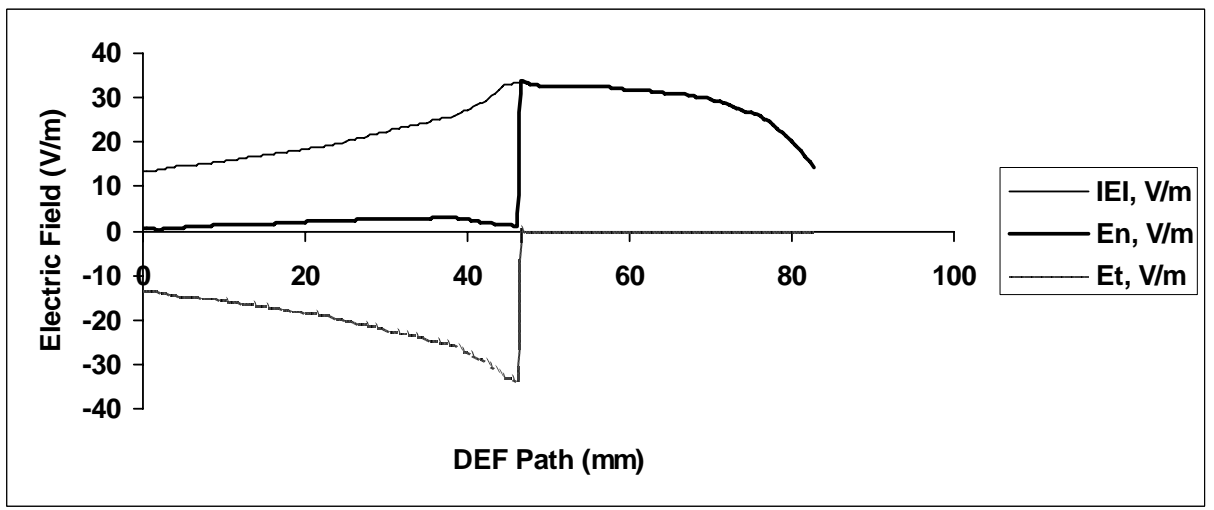

Figure 27. Electric field distribution along DEF path inside gas insulated bus duct

E. Electric field distribution around earthed particle contamination which adhered to discspacer

Figure 28 shows gas insulated bus duct with earthed particle contamination which adhered to disc spacer. The particle length (L) is taken as $5 \mathrm{~mm}$ and hemi-spherical radius (r) as $0.5 \mathrm{~mm}$. The distance between spacer and particle contamination (dsp) is taken as $0.26 \mathrm{~mm}$.

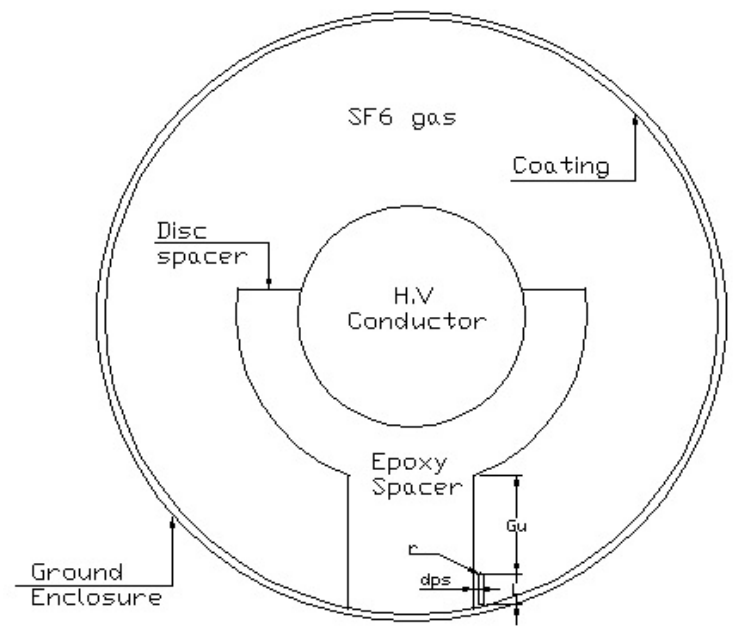

Figure 28. Gas insulated bus duct with earthed particle contamination which adhered to disc spacer 
Figure 29 shows the electric field distribution around earthed contaminating particle which adhered to disc spacer inside gas insulated bus duct. From this figure, it can be observed that the electric field is maximum value at triple junction point (c) of particle and this value decreases gradually as far from particle until it reaches to a certain point but it returns to increase slightly as near to high voltage conductor.

Triple Junction point (c) is conjunction between three materials (epoxy spacer, $\mathrm{SF}_{6}$ gas and $\mathrm{Al}$. particle).

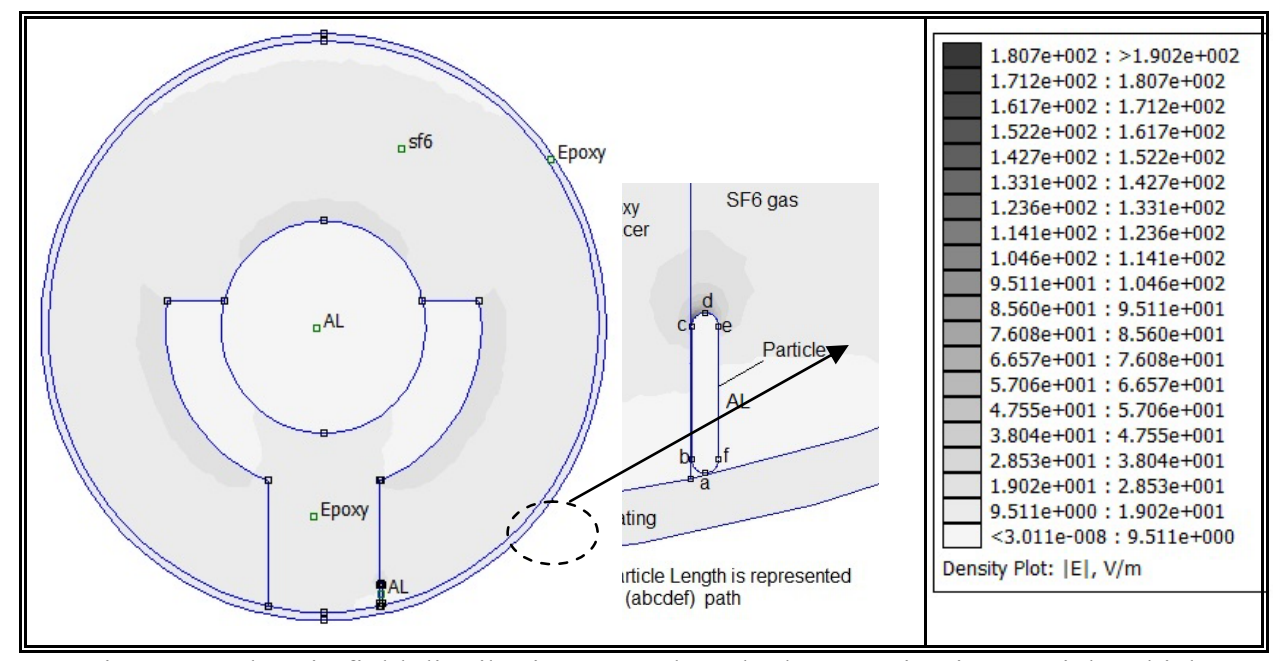

Figure 29 Electric field distribution around earthed contaminating particle which adhered to disc spacer inside gas insulated bus duct

Figure 30 shows magnitude, normal and tangential components of electric field distribution along particle length which adhered to disc spacer inside gas insulated bus duct. It can be observed that the tangential component of electric field is equal to zero along particle length. The normal component of electric field increases gradually from minimum value at lower tip of particle through negative side until it reaches maximum value at triple junction point(c) of particle and after that point, it returns to decrease along particle length from point $\mathrm{c}$ until it reaches the lower value at point (a). Finally, total component of electric field increases gradually from minimum value at point (a) of particle through point (b) until it reaches maximum value $(289 \mathrm{~V} / \mathrm{m})$ at triple junction point (c) of particle and after that point, it decreases along particle length from point (d) to point (f) until it reaches the minimum value at point (a) of particle.

Figure 31 shows magnitude, normal and tangential components of electric field distribution along upper gap space $(\mathrm{Gu})$ from triple junction point (c) of particle up to high voltage conductor inside gas insulated bus duct. It can be observed that the tangential component of electric field is about zero. The normal component of electric field decreases gradually through negative side from maximum value until it reaches a certain value through gap and then it slightly increased. Finally, total component of electric field decreases gradually through positive side from maximum maximum value at triple junction point (c) of particle until it reaches a certain value through gap and then it slightly increased as near to high voltage conductor. 


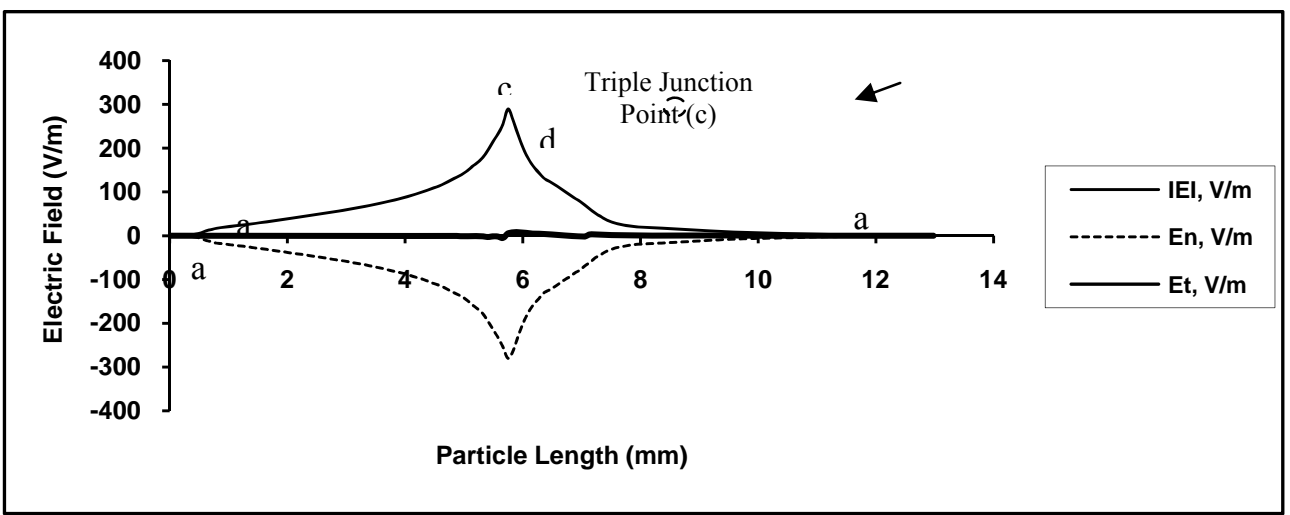

Figure 30. Electric field distribution along length of adhered particle to disc spacer inside gas insulated bus duct

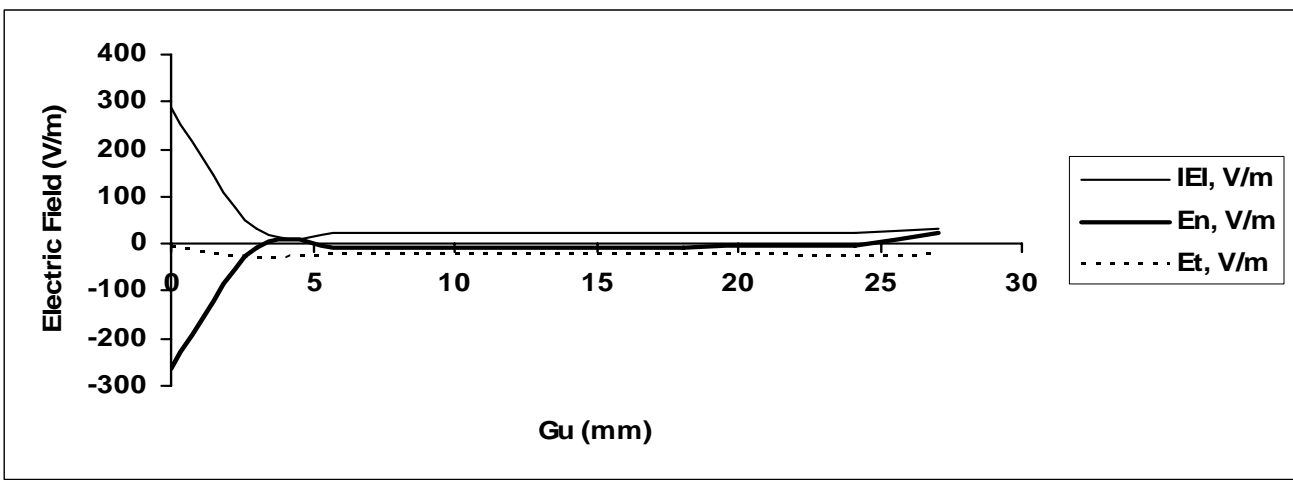

Figure 31. Electric field distribution along upper gap space $(\mathrm{Gu})$ from triple Junction point of particle up to high voltage conductor

(a) Effect of distance between particle and spacer on the electric field values

Figure 32 shows electric field distribution along particle length at different values of spacing between particle and spacer. From this figure, it can be observed that the electric field along particle length decreases as the distance between particle and spacer increases. The electric field is maximum value at triple junction point of particle when it adhered to spacer and then it decreases after triple junction point (c) of particle until it reaches the minimum value at lower tip of particle along (c-f-a) path as shown in Figure29. As the distance between particle and spacer increases, the maximum electric field is observed at hemi-spherical radius of particle from spacer side.

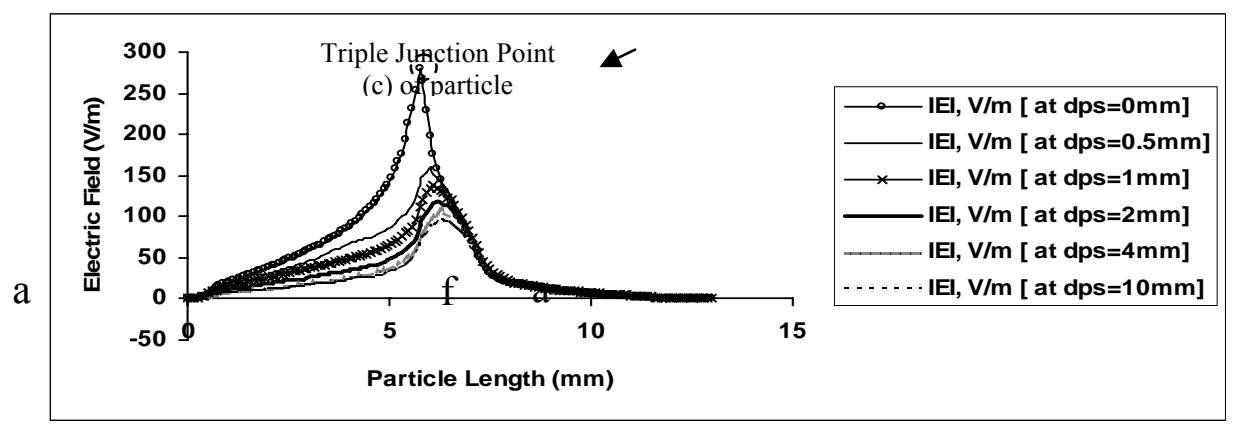

Figure 32 Electric field distribution along particle length at different values of spacing between particle and spacer 


\section{Conclusions}

In this study, electrostatic modeling of gas insulated bus duct which represented by two concentric cylinder of infinite length with gap with particle contamination and with dielectric coating of earthed enclosure are presented. From this work, when the particle is earthed on the enclosure of gas insulated bus duct, it can be observed that the electric field is minimum value at lower tip of particle and maximum value at upper tip of it and also the electric field decreases from upper tip of wire particle till reaches a certain value but after this value, it returns to increase till reaches to a certain value at inner conductor of gas insulated bus duct. When it studied the effect of particle dimensions on the maximum electric field, it has been observed that the maximum electric field at upper tip of wire particle increases as the particle length increases. Also as the wire particle radius increases, the electric field decreases. When the ratio of particle length to radius $(\mathrm{L} / \mathrm{r})$ increased, the electric field at upper tip of the wire particle increased also. The deleterious effect of electrode surface roughness has been reduced by coating the inner surface of enclosure of gas insulated bus duct (GIBD) with a dielectric material. There is a very small effect on the electric field values at upper tip of earthed wire particle whether without coating or with coating and also the variation of coating thickness from 0 to 2000 micro-meter has a small effect on the electric field values at upper tip of earthed wire particle. When Three fixed particles rested at ground enclosure, the electric field at upper tip of outermost particles is slightly greater than it at upper tip of middle particle and this is because the outermost particles which rested at ground enclosure is nearer to high voltage conductor than middle particle. When length of middle fixed particle increases at constant length of outermost particles, the maximum electric field at upper tip of middle particle increases also but it slightly decreased at upper tip of outermost particles. When radius of middle fixed particle increases at constant radius of outermost particles, the maximum electric field at upper tip of middle particle decreases and this means that the electric field is maximum at thin particles but it still approximately constant at upper tip of outermost particles. When the earthed particle is adhered to disc spacer inside gas insulated bus duct, the electric field is maximum value at triple junction point of particle and then it decreases after triple junction point of particle until it reaches the minimum value at lower tip of it. As the distance between particle and spacer increases, the maximum electric field is observed at hemi-spherical radius of particle from spacer side. The electric field decreases as the distance between particle and spacer increases. Finally, all these distributions of electric field inside gas insulated bus duct is very important to help us to predict the probability of occuring breakdown voltage for gas.

\section{References}

[1] Rauno Gordon, Tuukka Arola, Katrina Wendel, Outi Ryynanen and Jari Hyttinen, "Accuracy of numerical methods by calculating static and quasistatic electric fields", Proc. Estonian Acad. Sci. Eng., vol. 12, pp.262-283, 2006.

[2] Jawad Faiz, M. Ojaghi, "Instructive Review of Computation of Electric Fields using Different Numerical Techniques", International Journal of Engineering, vol. 18, no.3, pp. 344-356, 2002.

[3] D. Deepak Chowdary1, J.Amarnath2, "Electric Field Stress Analysis for a Compisite Cone Type Spacer Designed for Uniform Electric Field Distribution on Spacer Surface in the Presence of a Wire Like Particle", International Journal of Advances in Engineering \& Technology, ISSN: 2231-1963, Vol. 3, Issue 2, pp. 243-252, May 2012.

[4] R.M.Radwan, A.M.Abou-Elyazied, " Electric Field Distribution on Insulating Spacers in GIS Using the Finite Element Techniue", CIGRE, A3-104, pp. 1-7, 2006.

[5] Sayed A. Ward, M. A. Abd Allah, Amr A. Youssef, " Multi-Particle Initiated Breakdown of Gas Mixtures inside Compressed Gas Devices", Electrical Insulation and Dielectric Phenomena (CEIDP) Conference, IEEE, pp. 353-356, 2012.

[6] Amr Ameen Youssef, Mousa Abd Allah, Sayed Ward, " Particle Initiated Breakdown inside Gas Insulated Switchgear", LAP LAMBERT ACADEMIC PUBLISHING, e-book, ISBN: 978-3-659-26973-8, PP. 1-81, 2012. 
[7] David Meeker, "Finite Element Method Magnetics, Version 4.2, User's Manual", September 2006.

[8] K.B. Madhu Sahu and J. Amarnath," Movement of metallic particle contamination in a gas insulated busduct under dielectric coated enclosure with electromagnetic field effect", Indian Journal of Science and Technology, ISSN: 0974- 6846,Vol. 3, No. 7, pp. 764-769, July 2010.

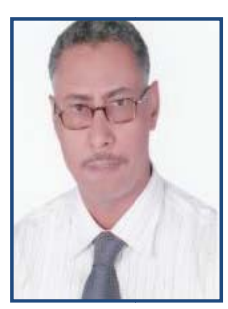

Mousa A. Abd-Allah was born in Cairo, Egypt, on August 16, 1961. He received the B.Sc. degree in electrical Engineering with honor in 1984 and the M.Sc. degree in High Voltage Engineering in 1988, both from Zagazig university, benha branch, Cairo, Egypt. He received the Ph.D. degree in High Voltage Engineering in 1992 from Cairo university. He is currently a professor with the Electrical Engineering department, Faculty of Engineering at Shoubra, Benha university. His research activity includes Electromagnetic Field Assessment and Mitigation around Electrical Equipments, Gas discharge in gas insulated systems, Electromagnetic Compatibility, Transient Phenomenon in Power Networks.

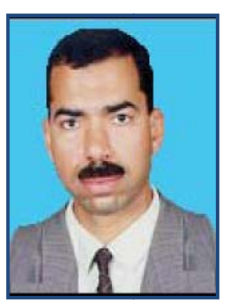

Sayed A. Ward was born in Cairo, Egypt, on December 24, 1961. He received the B.Sc. degree in electrical engineering with honor in 1984 and the M.Sc. degree in high-voltage Engineering in 1988, both from Zagazig University, Shoubra, Cairo, Egypt. He received the Ph.D. degree in highvoltage engineering in 1992 from Cairo University. He is currently a professor with the Electrical Engineering Department, Faculty of Engineering (Shoubra), Cairo, Egypt. His research activity includes studying the gas discharge phenomena in GIS, breakdown voltage study in GIS systems for compressed gases and gas mixtures. Also his research activity includes breakdown in Insulating Oils and DGA oil analysis in power transformers.

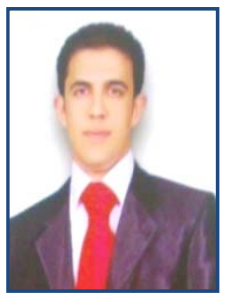

Amr A. Youssef was born in Cairo, Egypt, on July 31, 1985. He received the B.Sc. degree in electrical engineering with honor degree in 2007 from Faculty of Engineering at Shoubra, Benha University, Cairo, Egypt. On December 2008, he received his work in this faculty as an instructor in the Electrical Engineering Department. In 2011, he will receive the M.Sc. degree in electrical engineering from this faculty. Currently he is an assistant lecturer at Electrical Engineering Department in this faculty and also PH.D researcher in high voltage engineering. His research activity includes studying the characteristics of various gas mixtures, electric field and breakdown voltage calculations around single and multi-contaminating particles with various shapes of spacers inside GIS and GIBD. 